\title{
Why Hospital Workers Need Unions
}

\section{Toni Lewis and Howard S. Berliner*}

Department of Nutrition, New York University, USA

\section{Editorial}

As we struggle to lower health care costs in the U.S., it seems that our focus is often misplaced. Much as we try to make health care a technological enterprise, we know at heart it is a human endeavour. While robots might prove to be more adept than surgeons (though in the end they probably won't), it is people that provide us with hope and compassion and help us get through trying times. In our efforts to make health care less expensive, we neglect the outrageous salaries given to hospital and health care CEO's and their growing administrative minions but cut the hours of hospital environmental workers who keep us safe from infections; we spend hundreds of millions of dollars on unproven technologies like proton beam scanners while refusing to hire enough nurses to adequately provide care to patients; and we watch safety-net hospitals close and be converted to condo's while paying millions to bankruptcy lawyers and consultants. While the ACA has been a great mechanism for insuring many more Americans, its intent was not to address the health workforce in any direct manner. It should be noted that while the ACA required that a Commission on Health Workforce be established, to date it has not happened.

If we are to preserve a health care system that cares about people and not only about profits, we must protect health workers health and living conditions through a union. Only through collective action will we be able to take back the health system from the forces of profit and excess and ensure that it is focused on getting sick people healthy rather than getting rich people richer.

Perhaps the only industry to show continuous growth throughout the economic cycle in the United States has been the health care industry. Two factors stand out in recent reports on health care growth: 1) the concentration and consolidation of hospitals and health care facilities; and 2) the lack of growth in pay for non-clinical health care workers.

The stand-alone health care facility or hospital is quickly becoming a relic of the past as large organizations (largely for-profit) take over smaller not-for profit and public facilities in the name of economy but in the reality of higher costs and greater monopoly power. The merger and consolidation of facilities serves only the new owners and adds substantial costs to the health care economy, as many studies have shown.

The health sector in the U.S. now employs almost $15,000,000$ people or $10.7 \%$ of the total non-farm workforce. Data from the Bureau of Labour Statistics show that overall the health sector added 45,000 jobs in April 2015 (over employment in March, 2015). Of these new jobs, hospitals added 11,800 in April and ambulatory care jobs added 25,000 . This growth in workforce, while overall growth in health care spending remains low suggests that new workers are getting paid less in wages and benefits. At the same time, a recent CDC report shows that the health industry has the highest rate of non-fatal work related injuries of any private sector occupation, at $20 \%$ of the total. Another study showed that the health workforce had 7 times the rate of musculoskeletal injuries of other private sector industries. While
OSHA collects some data on workplace incidents, it collects very little from the hospital sector-but what it does collect is quite scary in terms of the level of violence against health care workers-particularly nurse aides- by patients.

The OSHA data show that nurse assistants were more likely to sustain injuries than workers in other job categories; this occupation had more than twice the injury rate of nurses for patient handling and workplace violence injuries. Injury rates for slips, trips, and falls were highest among non-patient care staff (e.g., maintenance and security staff), nursing assistants, and nurses. Between 2012 and 2014, workplace violence injury rates increased for all job classifications and nearly doubled for nurse assistants and nurses. Patient handling and workplace violence injury rates were highest in inpatient adult wards; these rates were also elevated in outpatient emergency departments, urgent care, and acute care centre and adult critical care departments.

While we deservedly pay a lot of attention to patient injuries and deaths due to medical errors and attempt to create mechanisms and programs to reduce them, we do not pay the same attention to the injuries of health care workers. Even when those injuries are publicized, as with the nurses in Texas who acquired Ebola because they did not have training in the correct use of protective garb, there is no national outcry for greater protection for health workers. It should be noted that the CDC data represents only the tip of the iceberg of workplace injury and violence.

Adding more workers to the health care system, as we are doing at an increasing clip, without providing more training and more assistive equipment will only increase the numbers of injuries to health personnel.

In the United States the only way that workers have received more protection, better wages and benefits, and a say in how the industry operates has been through unions. Given the circumstances described above, it is not surprising that health workers have the greatest union density of any other occupation, but still between $85-90 \%$ of health workers are not unionized and are at the mercy of venal health care companies seeking only to increase profits. There is a clear and compelling need for health worker unions to protect the people who provide our care and to preserve the values we hold dear in our health system.

*Corresponding author: Berliner SH, Department of Nutrition, Food Studies and Public Health, Steinhardt School, New York University, NY 10003, USA, Tel: +12129984500; E-mail: berliner@clarber.com

Received July 21, 2015; Accepted July 23, 2015; Published July 26, 2015

Citation: Lewis T, Berliner HS (2015) Why Hospital Workers Need Unions. Review Pub Administration Manag 3: e104. doi:10.4172/2315-7844.1000e104

Copyright: (c) 2015 Lewis T, et al. This is an open-access article distributed under the terms of the Creative Commons Attribution License, which permits unrestricted use, distribution, and reproduction in any medium, provided the original author and source are credited. 